\title{
A Review of the Associations Between Obstructive Sleep Apnea and Gestational Diabetes Mellitus and Possible Mechanisms of Disease
}

\author{
Xingyi Tong ${ }^{1,2} \cdot$ Linzhu Yang $^{3} \cdot$ Chengyan Jiang ${ }^{1,2} \cdot$ Zhiying Weng $^{4} \cdot$ Anju Zu ${ }^{1} \cdot$ Yunjiao Hou ${ }^{1} \cdot$ Yan Fang ${ }^{1,4}$. \\ Weimin Yang ${ }^{4}$. Shibo Sun ${ }^{1,4}$ (i)
}

Received: 19 April 2021 / Accepted: 25 February 2022 / Published online: 7 March 2022

(c) The Author(s) 2022

\begin{abstract}
Obstructive sleep apnea (OSA) usually leads to the occurrence of diabetes. Gestational diabetes mellitus (GDM) is a common gestational complication associated with adverse maternal and fetal outcomes. Increasing studies suggest that women with OSA during pregnancy may be at a significantly greater risk of developing GDM. It is crucial to explore the association between OSA and GDM and the mechanisms underlying this association. In this review, we presented a comprehensive literature review of the following: the association between OSA and GDM, the possible mechanisms of this association, and the effects of continuous positive airway pressure (CPAP) on OSA with GDM. The results showed that most authors suggested that there was an association between OSA and GDM. The intermittent hypoxemia (IH) and reduction of slow-wave sleep (SWS) may be the key to this association. IH induces the products of oxidative stress and inflammation as well as dysregulation of the hypothalamic-pituitary-adrenal, which lead to diabetes. In addition, SWS reduction in OSA enhances the inflammation by increasing the inflammatory cytokines, increases the sympathetic activation, and causes changes in leptin level, which result in the development of GDM. Additionally, whether CPAP is beneficial to GDM remains still unclear.
\end{abstract}

Keywords Obstructive sleep apnea $\cdot$ Sleep disorders $\cdot$ Gestational diabetes mellitus $\cdot$ Pregnancy $\cdot$ Obesity

\section{Introduction}

Obstructive sleep apnea (OSA) is characterized by recurrent intermittent hypoxemia (IH) and arousals during sleep. It is reported that OSA impairs glucose-induced insulin secretion from pancreatic $\beta$ cells and causes the aggregation of inflammatory factors in adipose tissue, leading to the occurrence of

Xingyi Tong and Linzhu Yang contributed equally to this work.

Shibo Sun

shibosunky@126.com

1 Department of Pulmonary and Critical Care Medicine, First Affiliated Hospital, Kunming Medical University, Kunming, China

2 Clinical Medicine \& Pediatrics, 2017 Grade, Kunming Medical University, Kunming, China

3 Thoracic Surgery, First Affiliated Hospital, Kunming Medical University, Kunming, China

4 School of Pharmaceutical Science \& Yunnan Key Laboratory of Pharmacology for Natural Products, Kunming Medical University, Kunming, China diabetes or insulin resistance (IR) [1, 2]. Continuous positive airway pressure (CPAP), as the gold standard for OSA treatment, improves diabetes or IR in OSA patients [3, 4]. Consequently, there is an association between OSA and diabetes, and this association is independent of adiposity and family history of diabetes [5, 6].

As a state of abnormal glucose tolerance, gestational diabetes mellitus (GDM) is a common gestational complication defined as any degree of glucose intolerance with onset or first recognition during pregnancy [7]. GDM is usually diagnosed at 24-28 weeks of pregnancy and is associated with adverse maternal and fetal outcomes [8-12]. In addition, mothers with GDM have an increased risk of preeclampsia, cesarean section, premature delivery, polyhydramnios, and infection [13-15]. The infants of a diabetic mother have an increased risk of neurodevelopmental deficits or physical defects $[13,16]$.

The associations between OSA and GDM may not be causal. Increasing evidence suggest that OSA is associated with GDM $[17,18]$. It is reported that the prevalence of OSA is $3.6-22 \%$ in different stages of pregnancy $[17,19,20]$. Bisson M. et al. estimated the prevalence of OSA in GDM 
is about $31 \%$ [21]. In addition, Facco FL. et al. found "highrisk" women (BMI $\geq 30 \mathrm{~kg} / \mathrm{m}^{2}$, hypertension, pre-pregnancy diabetes, preeclampsia, and/or twin pregnancy) had a much higher incidence of OSA from early pregnancy to the third trimester of pregnancy, ranging from 30 to $50 \%$ [22].

The mechanisms that link OSA to GDM are not yet clear. Moreover, continuous positive airway pressure (CPAP) is the gold standard treatment for OSA. So far, few studies have systematically explored the effect of CPAP on GDM with OSA. This article aimed to review the association between OSA and GDM, the possible mechanisms of association between OSA and GDM, and the effect of CPAP on OSA with GDM.

\section{Methods}

PubMed was used to search the articles published between March 1, 1977, and August 24, 2021. Search terms in PubMed included sleep apnea, sleep apnea syndrome, snoring, diabetes, pregnancy, pregnant, and mellitus. The articles were included, in which the OSA was diagnosed with polysomnography (PSG), home sleep testing monitor, or Watch-PAT, rather than symptom-based questionnaires, as some studies suggested that these questionnaires were not credible among pregnant women [23-25]. In addition, literature in languages other than English were excluded as well as the conference abstract or literature. The chart of the article screened is shown in Fig. 1.

\section{Results}

Twelve articles were finally included in this review (Tables 1 and 2), of which nine were prospective and three were case-control studies. In addition, seven articles included were published in the last five years. Among these articles, there were three randomized controlled trials (RCT) [26-28].

\section{Prevalence of OSA with GDM}

GDM occurred in $4.1 \%$ of women without pre-gestational diabetes [19]. Women with OSA developed GDM during
Fig. 1 Chart of article screened strategy. $O S A$, obstructive sleep apnea; GDM, gestational diabetes mellitus

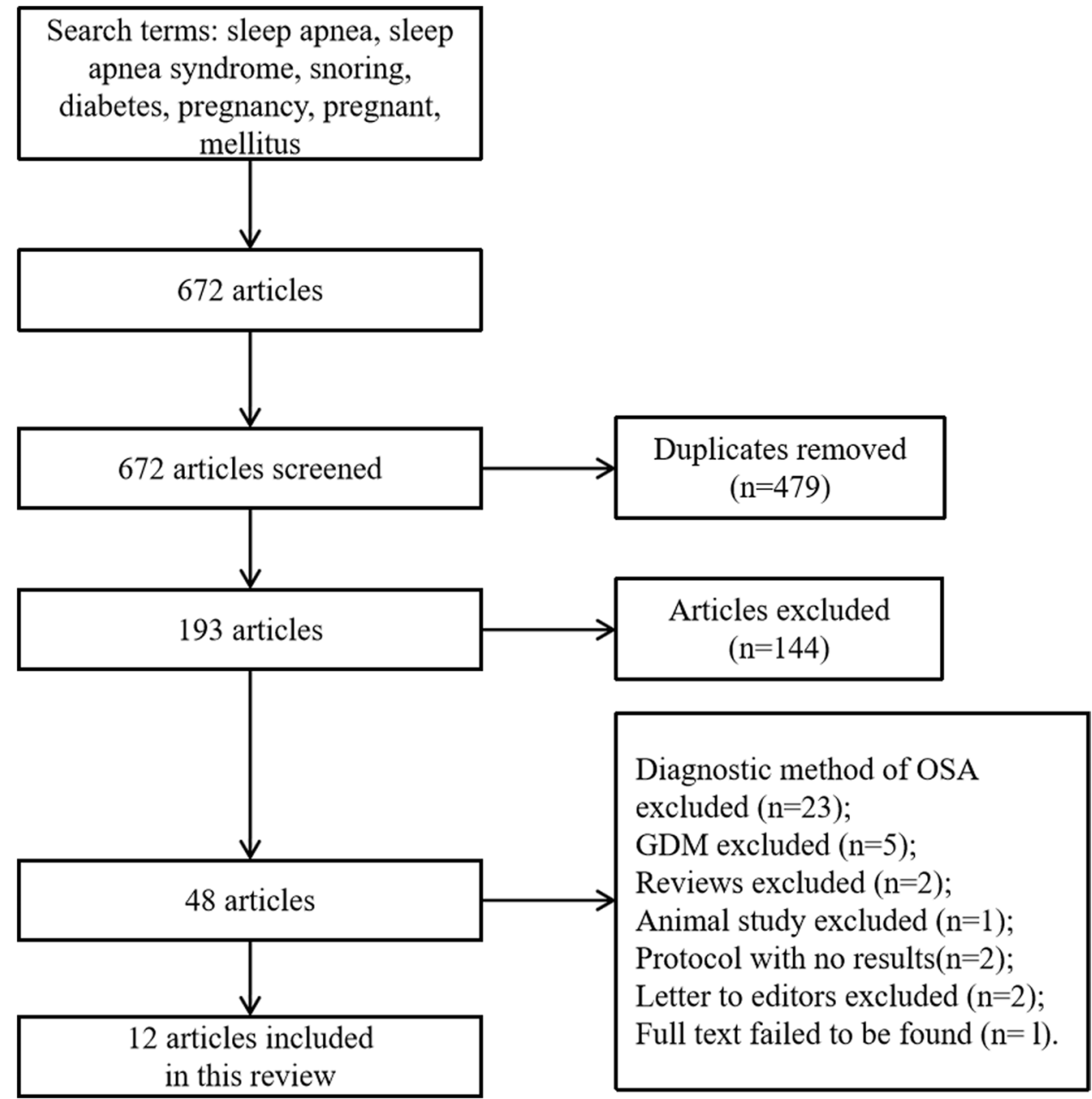




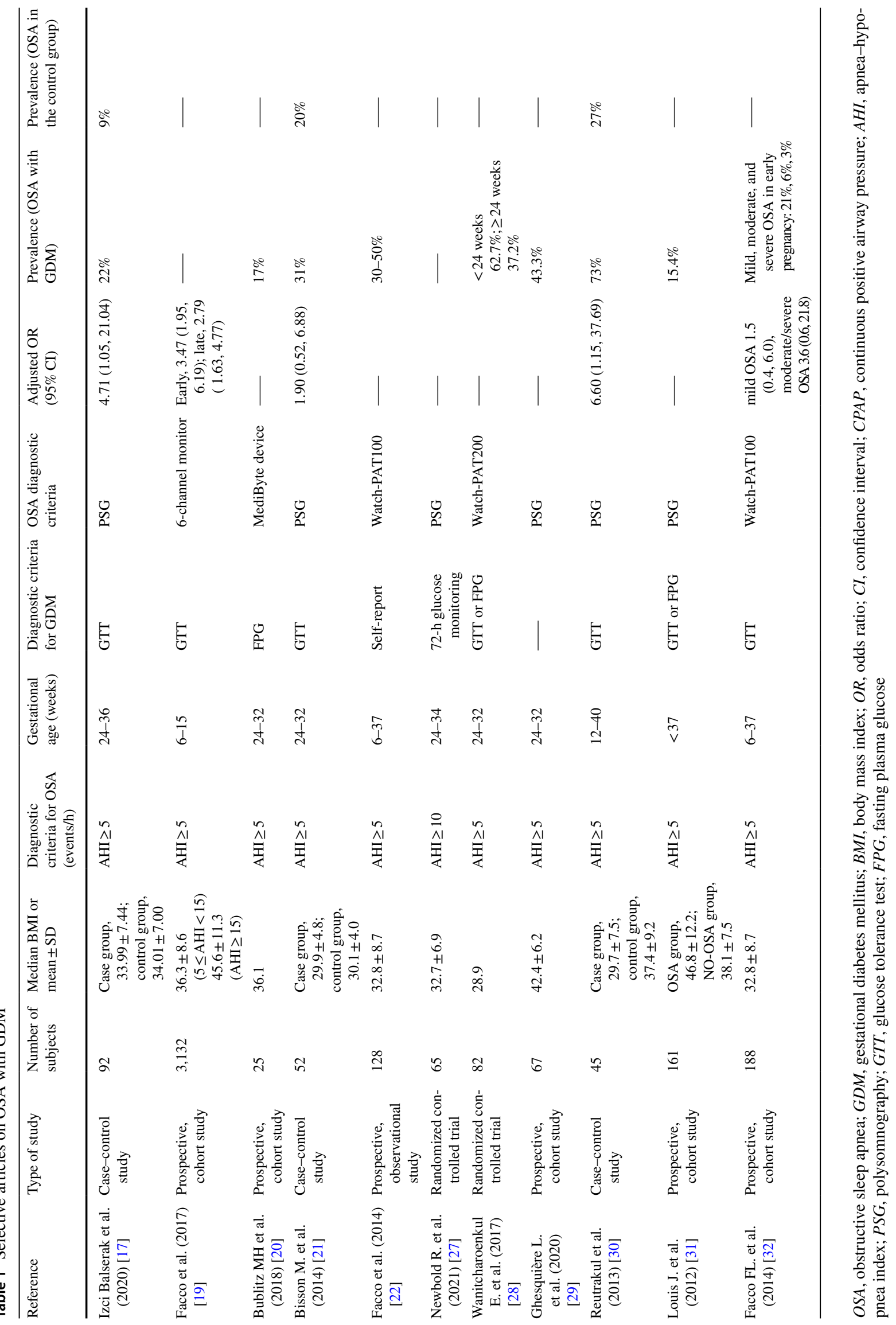




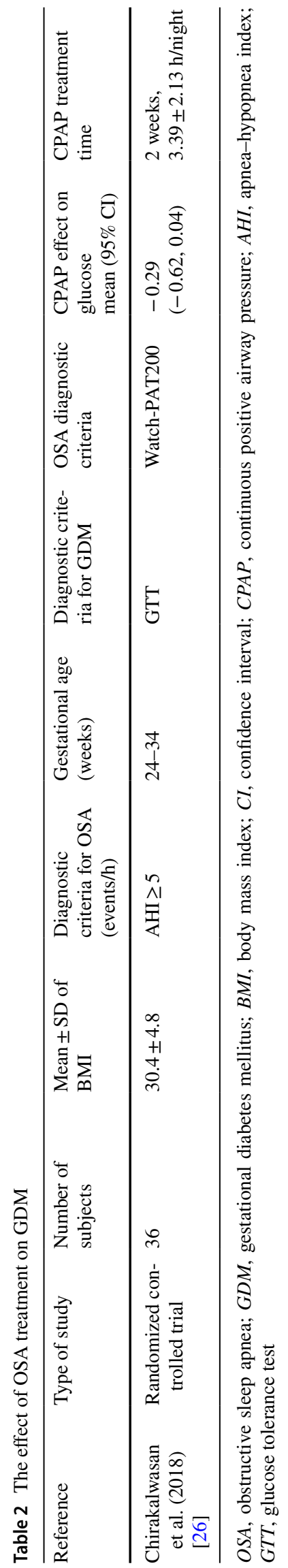

pregnancy more often [29]. A study suggested that the prevalence of GDM in pregnant women with OSA is higher than that without OSA: $48.3 \%$ compared with $23.7 \%$ [29]. It is reported that the prevalence of OSA with GDM is $4.1-73 \%$ and is increasing year by year [19, 28, 30, 31]. In addition, the prevalence of OSA with GDM presents $30-50 \%$ in different stages of pregnancy [33]. Facco FL. et al. considered that the prevalence of GDM in severe OSA was 35\% in the third trimester and $21 \%$ in early pregnancy [32]. However, Wanitcharoenkul E. suggested that the prevalence of GDM with OSA was $62.7 \%$ in early pregnancy and $37.2 \%$ in late pregnancy, respectively [28]. Moreover, the prevalence of GDM with OSA was $17 \%$ in a cohort consisting mainly of multigravida, multiparous, Caucasian women with GDM [20]. Accordingly, the prevalence of GDM with OSA varies widely in different studies.

\section{The Association Between OSA and GDM}

Studies indicated the risk that the GDM accompanying with OSA was much higher [20, 21]. It is reported that GDM risk was significantly higher among women with a higher overall apnea-hypopnea index (AHI) [odds ratio (OR), 1.81; 95\% CI, 1.01-3.27], higher AHI in REM (OR, 2.09; 95\% CI, 1.02-4.31), and higher oxygen desaturation index (OR, $2.21 ; 95 \%$ CI, 1.03-4.73) [17]. Consequently, there is an association between GDM and OSA [17, 30]. For the presence and absence of OSA, the adjusted OR (aOR) for GDM was 3.47 (95\% CI, 1.95-6.19) in early pregnancy [19]. In the second trimester of pregnancy, the severity of OSA was significantly associated with an increased risk of GDM even when the apnea-hypopnea index (AHI) was 1-5 events/h, which was below the standard threshold for OSA in nonpregnant women [21]. Additionally, the severity of OSA is correlated with IR, fasting glucose, and $\beta$-cell function [28]. Moreover, Chirakalwasan et al. explored the CPAP effect on GDM, and the results showed that $\beta$ cell function was significantly improved and a trend of improving fasting blood glucose levels was found in GDM adherent to CPAP in an RCT [26]. These results support that the OSA plays a vital role in GDM.

OSA is a complex sleep disorder including IH and reoccurrence of arousal, leading to sleep fragmentation, light sleep, low amounts of SWS, and usually reducing total sleep time [34, 35]. A randomized cross-sectional study indicated that there was an approximate $30 \%$ reduction of cellular insulin sensitivity in adipocytes from subcutaneous fat samples collected in healthy subjects after 4 nights of sleep restriction compared with 4 nights of normal sleep, leading to impaired insulin signal transduction and IR in human fat cells [36]. Reutrakul et al. [30] evaluated OSA in women with GDM using PSG, and the results showed that the sleep fragmentation degree and AHI in 
women with GDM was higher than that in normal pregnant women. Authors suggested that sleep fragmentation and SWS inhibition led to a decrease in insulin sensitivity [37, 38]. In addition, acute exposure to IH in healthy volunteers was associated with decreased insulin sensitivity and impaired glucose tolerance [39]. Moreover, higher arousal index and more frequent hypoxic desaturation events are associated with higher fasting blood glucose levels [38]. On the contrary, two studies suggested that there is no relationship between GDM and OSA [21, 32]. However, the BMI effect on OSA or GDM has not been completely eliminated in these studies. Consequently, there is an association between GDM and OSA [19, 40].

Obesity may be a confounding factor of the association between OSA and GDM. However, Bourjeily et al. confirmed that OSA was associated with GDM (aOR, 1.51; 95\% CI, 1.34-1.72) after adjusting for potential confounding factors (maternal obesity, pre-pregnancy hypertension, pre-pregnancy diabetes, maternal age, race/ethnicity, multiple births, tobacco use, alcohol use, drug use, rural/urban status, coronary heart disease, anemia, hyperlipidemia, hypothyroidism, disorders of the adrenal gland) in a study in which 1,577,632 deliveries women were included [40]. Moreover, GDM was found to be associated with the OSA (aOR, 6.60; 95\% CI, 1.15-37.96) after adjusting for prepregnancy BMI though the sample size was small in this case-control study [30]. After adjusting for potential confounding factors including age, gestational age, BMI, and race, another study suggested that women with OSA had a higher GDM risk (OR, 4.71; 95\% CI, 1.05-21.04) and GDM risk was also significantly higher among women with higher AHI (OR, 1.81; 95\% CI, 1.01-3.27) [17]. Consequently, there is an association between GDM and OSA after adjusting for age, BMI, chronic hypertension, and pregnancy-related weight gain or not $[19,30,40]$. In conclusion, there is an association between OSA and GDM, which may not be caused by obesity.

\section{The Mechanisms of Association Between OSA and GDM}

Normal pregnant women usually have mild IR resulting from changes of hormonal or alteration of endothelial function during pregnancy [41]. Therefore, even small changes in sleep parameters may make pregnant women to be more susceptible to hyperglycemia or GDM. GDM has the same risk factors and genetic susceptibility as type 2 diabetes, which is related to IR and impaired insulin secretion [41]. Though exact mechanisms of the association between OSA and GDM remain not completely clear, several mechanisms may be involved in this association (Fig. 2).

\section{Oxidative Stress and Inflammation}

Increased studies suggest that oxidative stress and inflammation are associated with endothelial dysfunction [18, 42-44]. For pregnant women with OSA, IH has a range of downstream effects on tissues and organs [33, 45]. These effects include increased oxidative stress, the release of proinflammatory, and activation of cytokines or transcription factors [46-48]. IH during OSA leads to the increase of oxidative stress, which activates the pro-inflammatory cascade and the inflammatory pathway, consequently causing dyslipidemia and IR $[47,49]$. In addition, cyclic reoxygenation after IH also promotes the production of reactive oxygen species (ROS) in OSA [50]. When ROS is accumulated, it will be eliminated by antioxidants [51]. However, excessive ROS that exceeds the antioxidant scavenging capacity often impairs the function of cells [52]. It is suggested that pancreatic cells are more vulnerable to oxygen stress than muscles, kidneys, and liver, which may be due to an inadequate antioxidant system [53]. Additionally, redox-sensitive transcription factors, such as nuclear factor kappa B (NF$\kappa \mathrm{B})$ and HIF-1, are usually induced by ROS [51, 54]. The activation of NF- $\mathrm{KB}$ induces the release of several cytokines, such as tumor necrosis factor $\alpha(\mathrm{TNF}-\alpha)$ and interleukin-1 (IL-1), thereby leading to the presence of inflammation $[51,55]$. Moreover, it is reported that IH upregulates CC chemokine family ligand 2 (CCL2) [56]. CCL2 is one of the key chemokines that regulate monocyte/macrophage migration and infiltration. Overexpressing CCL2 attracts inflammatory cells from the blood into adipose tissue and increases the number of macrophages, which cause metabolic phenotype to be deteriorated and then IR presents [57-59]. Consequently, the oxidative stress and inflammation induced by $\mathrm{IH}$ in OSA is an important factor in the pathogenesis of GDM.

Moreover, the reduction of SWS which presents in OSA may enhance the inflammation by increasing the concentration of TNF- $\alpha$, interleukin-6 (IL-6), and C-reactive protein (CRP) in circulation, which is involved in IR $[36,60]$. In the Cleveland Family Study, the reduction of sleep duration was also associated with increased TNF- $\alpha$ levels and increased habitual sleep time was associated with increased CRP and IL-6 levels [61]. Similarly, in the second and third trimesters, lower SWS and poorer sleep quality were found to be associated with higher levels of IL-6 [62]. TNF- $\alpha$ increases the phosphorylation of serine 307 of IRS-1 through JNK activation, which negatively modulates the interaction of stimuli with insulin receptors and the subsequent tyrosine phosphorylation of IRS-1, leading to impaired insulin signaling and $\beta$ cell function [63-65]. OSA leads to pancreatic $\beta$-cell dysfunction, which is manifested by impaired basal insulin secretion and leads to diabetes [66]. TNF- $\alpha$ could significantly increase the secretion of IL-6, while IL- 6 could reduce glucose transport [67]. In addition, IL-6 treatment 


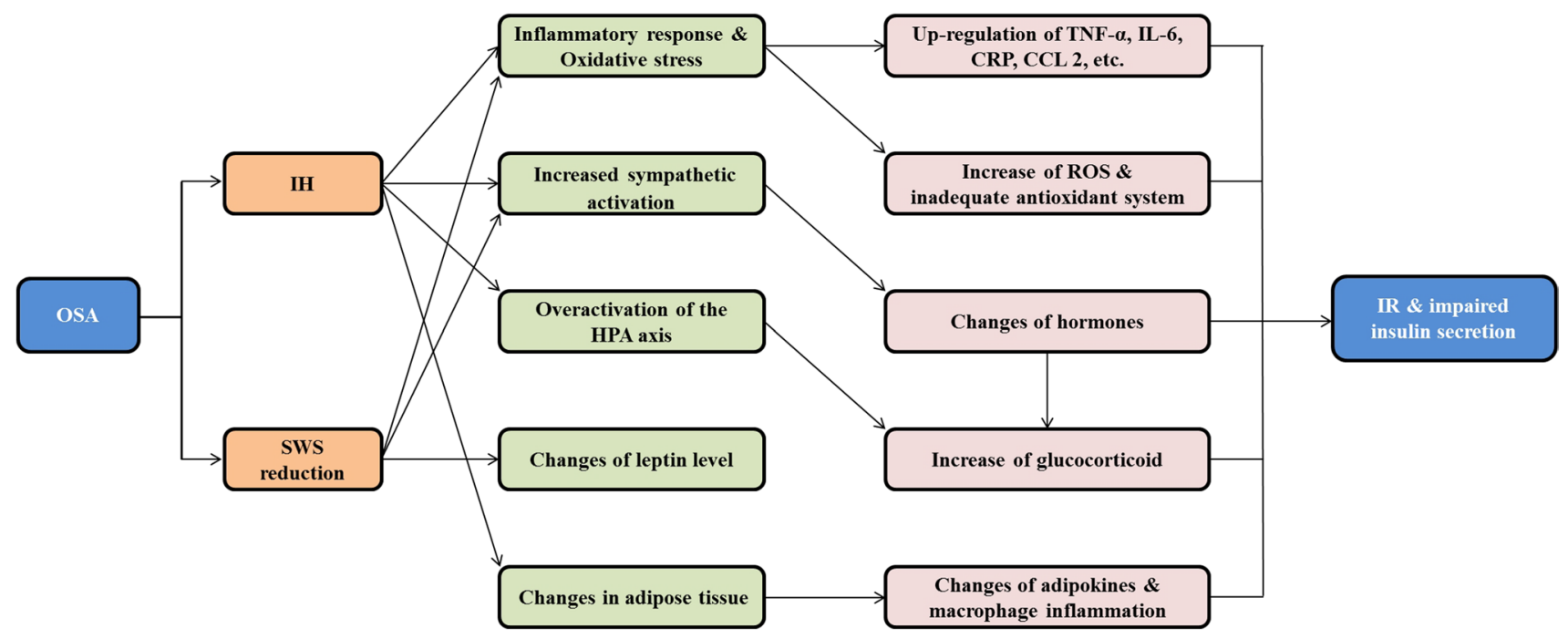

Fig. 2 The mechanism of gestational diabetes mellitus and insulin resistance induced by obstructive sleep apnea. $O S A$, obstructive sleep apnea; $I H$, intermittent hypoxemia; $S W S$, slow-wave sleep; $H P A$,

increases insulin-stimulated glucose disposal, glucose uptake, and fatty acid oxidation in vitro via AMP-activated protein kinase [68]. Thus, the oxidative stress and inflammation induced by changes in sleep structure in OSA is a vital factor in the pathogenesis of GDM.

\section{Increase of Sympathetic Activity}

In the general population, frequent arousal and hypoxia generally reduce SWS time and increase sympathetic activity, leading to wakefulness during sleep [47, 69-71]. The reduction of SWS time increases the brain's utilization of glucose and sympathetic nerve activity, which affect the regulation of glucose. In addition, when the sleep/ wake cycle is abnormal, dozing may disturb the changes in hormones which regulate glucose metabolism, appetite, and the balance between sympathetic and parasympathetic nerves, which may impair glucose tolerance [72, 73]. Consequently, increased sympathetic activation may lead to GDM [47, 74].

\section{Overactivation of the Hypothalamic-Pituitary-Adrenal (HPA) Axis}

The HPA axis consists of three cell populations and specific hormones secreted by each group cell. Neurons in the medial paraventricular cells of the hypothalamic paraventricular nucleus (PVN) secrete corticotropin-releasing hormone $(\mathrm{CRH})$, the endocrine cells of the anterior pituitary secrete adrenocorticotropic hormone (ACTH), and the endocrine cells in the adrenal cortical bundle mainly hypothalamic-pituitary-adrenal; $T N F$ - $a$, tumor necrosis factor $\alpha$; IL6, interleukin-6; $C R P, \mathrm{C}$-reactive protein; $C C L 2, \mathrm{CC}$ chemokine family ligand $2 ; R O S$, reactive oxygen species; $I R$, insulin resistance

secrete the corticosteroid [75-77]. HPA activation stimulates the synthesis and release of ACTH, and the ACTH subsequently promotes gluconeogenesis and regulates blood glucose levels [78]. It is reported that poor sleep quality in pregnancy is associated with elevated levels of nocturnal cortisol [79], which suggested that the effect of OSA on the HPA axis may be related to sleep deprivation. In addition, pro-inflammatory cytokines and IH may lead to excessive activation of the HPA axis, which subsequently increase the release of glucocorticoid [80-82]. Long-term augment of the glucocorticoid increases susceptibility to impaired IR and impaired glucose tolerance [83]. In addition, there are significant negative correlations between morning plasma cortisol levels and AHI, as well as oxygen desaturation index, which confirm that OSA is associated with dysregulation of the HPA axis and alterations in glucose metabolism with increased risk for diabetes [84]. Moreover, sleep disruption and IH during sleep in pregnant women with OSA may lead to activation of the HPA axis and increase cortisol levels, consequently increasing the risk of GDM [85]. Therefore, the hyperactivation of the HPA axis caused by sleep fragmentation, pro-inflammatory cytokines, and IH may play a vital role in the development of GDM in patients with OSA.

$\mathrm{CRH}$ is a hypothalamic neuropeptide which is produced and released from the placenta at intervals and plays a central role in regulating the HPA axis [86, 87]. Studies confirmed the relationship between OSA and placental dysfunction caused by hypoxia damage in OSA [88-90]. Consequently, the association between OSA with GDM may be mediated by the placenta regulating the HPA axis. 


\section{The Levels of Leptin}

Increasing evidence suggest that sleep deprivation, especially SWS loss, regulates appetite and satiety by reducing leptin sensitivity and increasing ghrelin levels, consequently boosting food intake and increasing IR [91, 92]. Leptin levels are higher in extreme situations where sleep time is shorter or longer [93]. Additionally, leptin levels were elevated in OSA and decreased after CPAP treatment, accompanying the increase of insulin secretion [94, 95]. Meanwhile, leptin is significantly associated with IR in patients with moderate-to-severe OSA [96]. However, the leptin levels in GDM are controversial. Some authors suggested that leptin levels were elevated in GDM and were associated with GDM status [97, 98], while other authors found there were no changes or reductions in leptin levels of GDM [99, 100]. Consequently, more studies are needed to confirm the role of leptin in the association between OSA and GDM.

\section{Adipose Tissue}

Obesity is associated with the presence of OSA and diabetes [101]. Obesity and particularly central adiposity are potent risk factors for sleep apnea [102]. At the same time, obesity in pregnancy is associated with the occurrence of GDM [103]. It seems that the increased prevalence of OSA in GDM patients results from obesity rather than the association between OSA and GDM. However, several studies confirm that OSA is still associated with GDM after adjusting for BMI [17, 30, 40], which means that obesity is not really the main factor contributing to the association between GDM and OSA. Authors suggested the maternal TNF- $\alpha$ level in circulation increased and was an independent predictor of GDM [104, 105]. Additionally, changes of adipokines induced by IH aggravate inflammation in adipose tissue, thereby leading to IR [106, 107]. Meanwhile, overexpression of monocyte-chemoattractant protein-1 (MCP-1) promotes the infiltration of monocytes/macrophages into adipose tissue and activates pro-inflammatory macrophages which are related to IR $[108,109]$. Moreover, the increased free fatty acids (FFA) induce macrophages to produce inflammatory cytokines by activating the NF- $\kappa B$ pathway, which is related to IR $[110,111]$. More importantly, pregnant women with OSA present an augment of the NF- $\mathrm{kB}$ pathway as well as macrophages inflammation $[47,112]$. Thus, inflammation of macrophages in adipose tissue of the OSA may be related to GDM. However, macrophages inflammation and its signal pathways in OSA with GDM remain unclear and require more research to confirm in the future.

\section{The Effect of OSA Treatment on GDM}

CPAP is the gold standard for the treatment of OSA and can reduce the occurrence of various complications [113, 114]. However, the effect of CPAP on glucose metabolism and adverse outcomes of pregnancy is still debated. The authors suggested that CPAP treatment of OSA significantly improved glycaemic control via amelioration of evening fasting glucose metabolism and a reduction in the dawn phenomenon and may be more beneficial in participants with poor glycemic control at baseline $[115,116]$. In addition, CPAP is beneficial to the decrease of glycated hemoglobin and improves $\beta$ cell function [117]. On the contrary, other authors suggest that therapeutic CPAP does not significantly improve glycaemic control or IR [118, 119].

Carnelio S. confirmed that CPAP does not prevent adverse outcomes of pregnant women (early miscarriage, premature deliveries, etc.) [120]. However, among participants who adhered to CPAP, there is a significant improvement in the hospitalization rates of premature births and unplanned cesarean sections and neonatal intensive care units were lower in mothers who used CPAP for $>2$ weeks than those who used CPAP for $\leq 2$ weeks $[26,121]$.

CPAP is a safe and effective method for pregnant women with OSA [122, 123]. It was reported that 2 weeks of CPAP treatment in late pregnancy was safe but did not improve glucose metabolism of OSA with GDM, though there was a tendency of improvement in fasting glucose [26]. However, CPAP treatment improved insulin secretion $(P=0.002)$ and insulin sensitivity of OSA with GDM $(P=0.015)$ after dealing with nonadherence in the RCT [26]. At present, it is uncertain whether the CPAP is beneficial to OSA with GDM because a single study with a small sample size $(n=36)$ was included in this review [26]. Accordingly, more research on CPAP effects on OSA with GDM are urgently needed.

\section{Discussions}

Currently, most of the studies suggest that there is an association between OSA and GDM. However, the exact mechanisms of this association remain unclear. There are several possible mechanisms involved in this association. Among these mechanisms, the IH and reduction of SWS were plausible. On the one hand, IH in OSA induces the products of oxidative stress and inflammation in adipose tissue or circulation, which lead to IR or diabetes [47, 49]. On the other hand, IH results in dysregulation of the HPA axis and thereby impairs glucose metabolism [80, 81]. In addition, SWS reduction plays an important role in the association between OSA and GDM. SWS reduction in OSA enhances the inflammation by increasing the inflammatory cytokines, increases the sympathetic activation, and causes the changes 
in leptin level, which result in the development of GDM [36, $60,72,73,91]$.

Obesity hypoventilation syndrome (OHS) may develop from a complex interaction between severe OSA, central obesity, obesity-related respiratory disorders, and reduced respiratory drive [124]. OSA is present in $90 \%$ of individuals with OHS, and the remaining $10 \%$ of OHS is characterized by an apnea-hypopnea index (AHI) $<5$ events/hour [125]. Currently, OHS is still poorly understood [126]. Most previous studies on OSA did not distinguish OHS from OSA, which means that the OSA subjects in these studies may have mixed with OHS patients. Similarly, we failed to separate OHS from OSA in this review due to the limitations of previous studies. Therefore, studies on the association between OSA and GDM are needed with the exclusion of OHS confounding in the future.

Moreover, studies are needed to explore the mechanisms of association between OSA and GDM. IH may up-regulate other factors besides resistin, TNF- $\alpha$, and CCL2. Cytokines or inflammatory factors which strongly contribute to GDM are needed to find. Additionally, the insulin downstream signal of insulin regulated by cytokines remains unclear. Meanwhile, the effect of leptin levels in GDM is still debated. In addition, clinical trials should be designed to confirm the effect of CPAP on the maternal and fetal outcomes of GDM.

There were several limitations in this review. Firstly, some studies included presented a small sample size. Secondly, studies included failed to distinguish OHS from OSA. Thirdly, among the twelve studies included, there are only three RCTs. Another limitation is that none of the included studies listed the type of obesity and gestational weight gain, which may be a confounding factor. However, these limitations pointed to the direction of future research. Meanwhile, several strengths were presented in this review. In addition, the studies in which OSA subjects diagnosed with a questionnaire were excluded.

In conclusion, researchers should pay more attention to the association between OSA and GDM in the future. More studies should focus on mechanisms of this association as well as the CPAP effects on the OSA with GDM.

Acknowledgements Thanks to the support of the National Natural Science Foundation of China, Yunnan Provincial Science and Technology Department, and Yunnan Provincial Educational Department.

\footnotetext{
Author Contribution All authors contributed to the study's conception and design. Material preparation, data collection, and analysis were performed by Xingyi Tong, Linzhu Yang, Chengyan Jiang, Zhiying Weng, Anju Zu, Yunjiao Hou, Yan Fang, Weimin Yang, and Shibo Sun. The first draft of the manuscript was written by Xingyi Tong, and all authors commented on previous versions of the manuscript. All authors read and approved the final manuscript.
}

Funding The present study was funded by the Yunnan Provincial Science and Technology Department [Nos. 2019FE001 (-058),
2017FE467 (-019), 2018FE001 (-026), 2017IC041], Yunnan Provincial Department of Education (Nos. 2018JS161, 2017zzx201), and Teaching and Reform Program of Kunming Medical University (Nos. 2017JY-Y-040, 2016-JY-Y-43). The funders had no role in study design, data collection and analysis, decision to publish, or preparation of the manuscript.

Data Availability Not applicable.

Code Availability Not applicable.

\section{Declarations}

Ethics Approval Our study did not involve humans or animals, so ethical approval is not required.

Consent to Participate Not applicable.

Consent for Publication Not applicable.

Conflict of Interest The authors declare no competing interests.

Open Access This article is licensed under a Creative Commons Attribution 4.0 International License, which permits use, sharing, adaptation, distribution and reproduction in any medium or format, as long as you give appropriate credit to the original author(s) and the source, provide a link to the Creative Commons licence, and indicate if changes were made. The images or other third party material in this article are included in the article's Creative Commons licence, unless indicated otherwise in a credit line to the material. If material is not included in the article's Creative Commons licence and your intended use is not permitted by statutory regulation or exceeds the permitted use, you will need to obtain permission directly from the copyright holder. To view a copy of this licence, visit http://creativecommons.org/licenses/by/4.0/.

\section{References}

1. Ota H, Fujita Y, Yamauchi M, Muro S. Relationship between intermittent hypoxia and type 2 diabetes in sleep apnea syndrome. Int J Mol Sci. 2019;20(19):4756. https://doi.org/10.3390/ ijms20194756.

2. Kakutani-Hatayama M, Kadoya M, Morimoto A, et al. Associations of sleep quality, sleep apnea and autonomic function with insulin secretion and sensitivity: HSCAA study. Metabol Open. 2020;19(6):100033. https://doi.org/10.1016/j.metop.2020. 100033.

3. Martínez-Cerón E, Barquiel B, Bezos AM, et al. Effect of continuous positive airway pressure on glycemic control in patients with obstructive sleep apnea and type 2 diabetes. A randomized clinical trial. Am J Respir Crit Care Med. 2016;194(4):476-85. https://doi.org/10.1164/rccm.201510-1942OC.

4. Gharsalli H, Oueslati I, Sahnoun I, et al. Effect of continuous positive airway pressure on glycated hemoglobin in patients with type 2 diabetes and obstructive sleep apnea. Tunis Med. 2019;97(12):1345-52.

5. Nagayoshi M, Punjabi NM, Selvin E, et al. Obstructive sleep apnea and incident type 2 diabetes. Sleep Med. 2016;25:156-61. https://doi.org/10.1016/j.sleep.2016.05.009.

6. Li KK, Kushida C, Powell NB, et al. Obstructive sleep apnea syndrome: a comparison between Far-East Asian and white 
men. Laryngoscope. 2000;110:1689-93. https://doi.org/10.1097/ 00005537-200010000-00022.

7. Tsakiridis I, Giouleka S, Mamopoulos A, et al. Diagnosis and management of gestational diabetes mellitus: an overview of national and international guidelines. Obstet Gynecol Surv. 2021;76(6):367-81. https://doi.org/10.1097/OGX.0000000000 000899.

8. Metzger BE, Gabbe SG, Persson B, et al. International association of diabetes and pregnancy study groups recommendations on the diagnosis and classification of hyperglycemia in pregnancy. Diabetes Care. 2010;33:676-82. https://doi.org/10.2337/ dc09-1848.

9. Agarwal MM, Dhatt GS, Shah SM. Gestational diabetes mellitus: simplifying the international association of diabetes and pregnancy diagnostic algorithm using fasting plasma glucose. Diabetes Care. 2010;33:2018-20. https://doi.org/10.2337/dc10-057.

10. Dahanayaka NJ, Agampodi SB, Ranasinghe OR, et al. Inadequacy of the risk factor based approach to detect gestational diabetes mellitus. Ceylon Med J. 2012;57:5-9. https://doi.org/ 10.4038/cmjv57i1.4193.

11. Jenum AK, Morkrid K, Sletner L, et al. Impact of ethnicity on gestational diabetes identified with the WHO and the modified International Association of Diabetes and Pregnancy Study Groups criteria: a population-based cohort study. Eur J Endocrinol. 2012;166:317-24. https://doi.org/10.1530/EJE-11-0866.

12. Mission JF, Ohno MS, Cheng YW, et al. Gestational diabetes screening with the new IADPSG guidelines: a cost-effectiveness analysis. Am J Obstet Gynecol. 2012;207:326.e321-329. https:// doi.org/10.1016/j.ajog.2012.06.048.

13. Catalano PM, McIntyre HD, Cruickshank JK, et al. The hyperglycemia and adverse pregnancy outcome study: associations of GDM and obesity with pregnancy outcomes. Diabetes Care. 2012;35:780-6. https://doi.org/10.2337/dc11-1790.

14. Lowe LP, Metzger BE, Lowe WL, et al. Inflammatory mediators and glucose in pregnancy: results from a subset of the hyperglycemia and adverse pregnancy outcome (HAPO) study. J Clin Endocrinol Metab. 2010;95:5427-34. https://doi.org/10.1210/jc. 2010-1662.

15. Metzger BE, Lowe LP, Dyer AR, et al. Hyperglycemia and adverse pregnancy outcomes. N Engl J Med. 2008;358:19912002. https://doi.org/10.1056/NEJMoa0707943.

16. Van Lieshout RJ, Voruganti LP. Diabetes mellitus during pregnancy and increased risk of schizophrenia in offspring: a review of the evidence and putative mechanisms. J Psychiatry Neurosci. 2008;33:395-404. https://doi.org/10.1016/j.ajog.2012.06.048.

17. Izci Balserak B, Pien GW, Prasad B, et al. Obstructive sleep apnea is associated with newly diagnosed gestational diabetes mellitus. Ann Am Thorac Soc. 2020;17:754-61. https://doi.org/ 10.1513/AnnalsATS.201906-4730C.

18. Bublitz MH, Carpenter M, Amin S, et al. The role of inflammation in the association between gestational diabetes and obstructive sleep apnea: a pilot study. Obstet Med. 2018;11:186-91. https://doi.org/10.1177/1753495X18780095.

19. Facco FL, Parker CB, Reddy UM, et al. Association between sleep-disordered breathing and hypertensive disorders of pregnancy and gestational diabetes mellitus. Obstet Gynecol. 2017;129:31-41. https://doi.org/10.1097/AOG.0000000000 001805 .

20. Bublitz MH, Monteiro JF, Caraganis A, et al. Obstructive sleep apnea in gestational diabetes: a pilot study of the role of the hypothalamic-pituitary-adrenal axis. J Clin Sleep Med. 2018;14(1):87-93. https://doi.org/10.5664/jcsm.6888.

21. Bisson M, Series F, Giguere Y, et al. Gestational diabetes mellitus and sleep-disordered breathing. Obstet Gynecol. 2014;123:63441. https://doi.org/10.1097/AOG.0000000000000143.
22. Facco FL, Ouyang DW, Zee PC, et al. Sleep disordered breathing in a high-risk cohort prevalence and severity across pregnancy. Am J Perinatol. 2014;31:899-904. https://doi.org/10.1055/s0033-1363768.

23. Facco FL, Ouyang DW, Zee PC, et al. Development of a pregnancy-specific screening tool for sleep apnea. J Clin Sleep Med. 2012;8:389-94. https://doi.org/10.5664/jcsm.2030.

24. Lockhart EM, Ben Abdallah A, Tuuli MG, et al. Obstructive sleep apnea in pregnancy: assessment of current screening tools. Obstet Gynecol. 2015;126:93-102. https://doi.org/10.1097/AOG. 0000000000000848

25. Olivarez SA, Maheshwari B, McCarthy M, et al. Prospective trial on obstructive sleep apnea in pregnancy and fetal heart rate monitoring. Am J Obstet Gynecol. 2010;202:552.e551-557. https://doi.org/10.1016/j.ajog.2009.12.008.

26. Chirakalwasan N, Amnakkittikul S, Wanitcharoenkul E, et al. Continuous positive airway pressure therapy in gestational diabetes with obstructive sleep apnea: a randomized controlled trial. J Cli nSleep Med. 2018;14:327-36. https://doi.org/10. 5664/jcsm.6972.

27. Newbold R, Benedetti A, Kimoff RJ, et al. Maternal sleepdisordered breathing in pregnancy and increased nocturnal glucose levels in women with gestational diabetes mellitus. Chest. 2021;159(1):356-65. https://doi.org/10.1016/j.chest. 2020.07.014.

28. Wanitcharoenkul E, Chirakalwasan N, Amnakkittikul S, et al. Obstructive sleep apnea and diet-controlled gestational diabetes. Sleep Med. 2017;39:101-7. https://doi.org/10.1016/j.sleep. 2017.08.010.

29. Ghesquière L, Deruelle P, Ramdane Y, et al. Obstructive sleep apnea in obese pregnant women: a prospective study. PLoS ONE. 2020;15(9):e0238733. https://doi.org/10.1371/journal. pone. 0238733

30. Reutrakul S, Zaidi N, Wroblewski K, et al. Interactions between pregnancy, obstructive sleep apnea, and gestational diabetes mellitus. J Clin Endocrinol Metab. 2013;98:4195-202. https:// doi.org/10.1210/jc.2013-2348.

31. Louis J, Auckley D, Miladinovic B, et al. Perinatal outcomes associated with obstructive sleep apnea in obese pregnant women. Obstet Gynecol. 2012;120(5):1085-92. https://doi. org/10.1097/AOG.0b013e31826eb9d8.

32. Facco FL, Ouyang DW, Zee PC, et al. Implications of sleepdisordered breathing in pregnancy. Am J Obstet Gynecol. 2014;210(6):559.e1-6. https://doi.org/10.1016/j.ajog.2013. 12.035 .

33. Dominguez JE, Krystal AD, Habib AS. Obstructive sleep apnea in pregnant women: a review of pregnancy outcomes and an approach to management. Anesth Analg. 2018;127(5):116777. https://doi.org/10.1213/ANE.0000000000003335.

34. Tasali E, Leproult R, Ehrmann DA, et al. Slow-wave sleep and the risk of type 2 diabetes in humans. Proc Natl Acad Sci U S A. 2008;105:1044-9. https://doi.org/10.1073/pnas.07064 46105.

35. Martínez-Cerón E, Casitas R, Galera R, et al. Contribution of sleep characteristics to the association between obstructive sleep apnea and dyslipidemia. Sleep Med. 2021;84:63-72. https://doi. org/10.1016/j.sleep.2021.05.012.

36. Broussard JL, Ehrmann DA, Van Cauter E, et al. Impaired insulin signaling in human adipocytes after experimental sleep restriction: a randomized, crossover study. Ann Intern Med. 2012;157:549-57. https://doi.org/10.7326/0003-4819-157-8201210160-00005.

37. Huang W, Liu Y, Wang X, et al. Effect of interaction between slow wave sleep and obstructive sleep apnea on insulin resistance: a large-scale study. Nat Sci Sleep. 2021;13:739-49. https:// doi.org/10.2147/NSS.S311130. 
38. Stamatakis KA, Punjabi NM. Effects of sleep fragmentation on glucose metabolism in normal subjects. Chest. 2010;137:95-101. https://doi.org/10.1378/chest.09-0791.

39. Peng CS, Cao YA, Tian YH, et al. Features of continuous glycemic profile and glycemic variability in patients with obstructive sleep apnea syndrome. Diabetes Res Clin Pract. 2017;134:10612. https://doi.org/10.1016/j.diabres.2017.08.010.

40. Bourjeily G, Danilack VA, Bublitz MH, et al. Obstructive sleep apnea in pregnancy is associated with adverse maternal outcomes: a national cohort. Sleep Med. 2017;38:50-7. https://doi. org/10.1016/j.sleep.2017.06.035.

41. Mordwinkin NM, Ouzounian JG, Yedigarova L, et al. Alteration of endothelial function markers in women with gestational diabetes and their fetuses. J Matern Fetal Neonatal Med. 2013;26:50712. https://doi.org/10.3109/14767058.2012.736564.

42. Jelic S, Padeletti M, Kawut SM, et al. Inflammation, oxidative stress, and repair capacity of the vascular endothelium in obstructive sleep apnea. Circulation. 2008;117:2270-8. https://doi.org/ 10.1161/CIRCULATIONAHA.107.741512.

43. Choi SW, Ho CK. Antioxidant properties of drugs used in type 2 diabetes management: could they contribute to, confound or conceal effects of antioxidant therapy? Redox Rep. 2018;23(1):1-24. https://doi.org/10.1080/13510002.2017.1324381.

44. Odegaard AO, Jacobs DR Jr, Sanchez OA, et al. Oxidative stress, inflammation, endothelial dysfunction and incidence of type 2 diabetes. Cardiovasc Diabetol. 2016;24(15):51. https://doi.org/ 10.1186/s12933-016-0369-6.

45. Badran M, Yassin BA, Lin DTS, et al. Gestational intermittent hypoxia induces endothelial dysfunction, reduces perivascular adiponectin and causes epigenetic changes in adult male offspring. J Physiol. 2019;597(22):5349-64. https://doi.org/10. 1113/JP277936.

46. Mallard AR, Hollekim-Strand SM. High day-to-day and diurnal variability of oxidative stress and inflammation biomarkers in people with type 2 diabetes mellitus and healthy individuals. Redox Rep. 2020;25(1):64-9. https://doi.org/10.1080/13510002. 2020.1795587.

47. Izci-Balserak B, Pien GW, Fung AM, et al. Sleep-disordered breathing and pregnancy: potential mechanisms and evidence for maternal and fetal morbidity. Curr Opin Pulm Med. 2010;16:574-82. https://doi.org/10.1111/jsr.12656.

48. Lavie L. Oxidative stress inflammation and endothelial dysfunction in obstructive sleep apnea. Front Biosci (Elite Ed). 2012;4:1391-403. https://doi.org/10.2741/469.

49. Martins FO, Sacramento JF, Olea E. Chronic intermittent hypoxia induces early-stage metabolic dysfunction independently of adipose tissue deregulation. Antioxidants (Basel). 2021;10(8):1233. https://doi.org/10.3390/antiox10081233.

50. Prabhakar NR. Oxygen sensing during intermittent hypoxia: cellular and molecular mechanisms. J Appl Physiol. 2001;90:198694. https://doi.org/10.1152/jappl.2001.90.5.1986hypo.

51. Lavie L. Obstructive sleep apnoea syndrome - an oxidative stress disorder. Sleep Med Rev. 2003;7:35-51. https://doi.org/10.1053/ smrv.2002.0261.

52. Guzman DC, Olguín HJ, García EH, et al. Mechanisms involved in the development of diabetic retinopathy induced by oxidative stress. Redox Rep. 2017;22(1):10-6. https://doi.org/10.1080/ 13510002.2016.1205303.

53. Xu J, Long YS, Gozal D, et al. Beta-cell death and proliferation after intermittent hypoxia: role of oxidative stress. Free Radic Biol Med. 2009;46(6):783-90. https://doi.org/10.1016/j.freer adbiomed.2008.11.026.

54. Movafagh S, Crook S, Vo K. Regulation of hypoxia-inducible factor-1a by reactive oxygen species: new developments in an old debate. J Cell Biochem. 2015;116:696-703. https://doi.org/ $10.1002 /$ jcb.25074.
55. Collins T, Cybulsky MI. NF-kappaB: pivotal mediator or innocent bystander in atherogenesis? J Clin Invest. 2001;107(3):25564. https://doi.org/10.1172/JCI10373.

56. Uchiyama T, Itaya-Hironaka A, Yamauchi A, et al. Intermittent hypoxia up-regulates CCL2, RETN, and TNF $\alpha$ mRNAs in adipocytes via down-regulation of miR-452. Int J Mol Sci. 2019;20:1960. https://doi.org/10.3390/ijms20081960.

57. Anderson EK, Gutierrez DA, Hasty AH. Adipose tissue recruitment of leukocytes. Curr Opin Lipidol. 2010;21:172-7. https:// doi.org/10.1097/MOL.0b013e3283393867.

58. Deshmane SL, Kremlev S, Amini S, et al. Monocyte chemoattractant protein-1 (MCP-1): an overview. J Interferon Cytokine Res. 2009;29:313-26. https://doi.org/10.1089/jir.2008.0027.

59. Kanda H, Tateya S, Tamori Y, et al. MCP-1 contributes to macrophage infiltration into adipose tissue, insulin resistance, and hepatic steatosis in obesity. J Clin Invest. 2006;116:1494-505. https://doi.org/10.1172/JCI26498.

60. Thomas KS, Motivala S, Olmstead R, et al. Sleep depth and fatigue: role of cellular inflammatory activation. Brain Behav Immun. 2011;25:53-8. https://doi.org/10.1016/j.bbi.2010.07. 245.

61. Patel SR, Zhu X, Storfer-Isser A, et al. Sleep duration and biomarkers of inflammation. Sleep. 2009;32:200-4. https://doi.org/ 10.1093/sleep/32.2.200.

62. Okun ML, Hall M, Coussons-Read ME. Sleep disturbances increase interleukin-6 production during pregnancy: implications for pregnancy complications. Reprod Sci. 2007;14:560-7. https:// doi.org/10.1177/1933719107307647.

63. Fasshauer M, Bluher M, Stumvoll M. Adipokines in gestational diabetes. Lancet Diabetes Endocrinol. 2014;2:488-99. https:// doi.org/10.1016/S2213-8587(13)70176-1.

64. Starkie R, Ostrowski SR, Jauffred S, et al. Exercise and IL-6 infusion inhibit endotoxin-induced TNF-alpha production in humans. Faseb J. 2003;17:884-6. https://doi.org/10.1096/fj.02-0670fje.

65. Lee YH, Giraud J, Davis RJ, et al. c-Jun N-terminal kinase (JNK) mediates feedback inhibition of the insulin signaling cascade. J Biol Chem. 2003;278:2896-902. https://doi.org/10.1074/jbc. M208359200.

66. Wang N, Khan SA, Prabhakar NR, et al. Impairment of pancreatic $\beta$-cell function by chronic intermittent hypoxia. Exp Physiol. 2013;98(9):1376-85. https://doi.org/10.1113/expphysiol.2013. 072454.

67. Rotter V, Nagaev I, Smith U. Interleukin-6 (IL-6) induces insulin resistance in 3T3-L1 adipocytes and is, like IL-8 and tumor necrosis factor-alpha, overexpressed in human fat cells from insulin-resistant subjects. J Biol Chem. 2003;278:45777-84. https://doi.org/10.1074/jbc.M301977200.

68. Carey AL, Steinberg GR, Macaulay SL, et al. Interleukin-6 increases insulin-stimulated glucose dispOSAl in humans and glucose uptake and fatty acid oxidation in vitro via AMP-activated protein kinase. Diabetes. 2006;55:2688-97. https://doi.org/ 10.2337/db05-1404.

69. Punjabi NM. Do sleep disorders and associated treatments impact glucose metabolism? Drugs. 2009;69(Suppl 2):13-27. https:// doi.org/10.2165/11531150-000000000-00000.

70. Ruzicka M, Knoll G, Leenen FHH, et al. Effects of CPAP on blood pressure and sympathetic activity in patients with diabetes mellitus, chronic kidney disease, and resistant hypertension. CJC Open. 2020;2(4):258-64. https://doi.org/10.1016/j.cjco.2020.03. 010 .

71. Ukraintseva YV, Liaukovich KM, Saltykov KA, Belov DA, Nizhnik AN. Selective slow-wave sleep suppression affects glucose tolerance and melatonin secretion The role of sleep architecture. Sleep Med. 2020;67:171-83. https://doi.org/10.1016/j.sleep. 2019.11.1254. 
72. Izci Balserak B, Jackson N, Ratcliffe SA, et al. Sleep-disordered breathing and daytime napping are associated with maternal hyperglycemia. Sleep Breath. 2013;17:1093-102. https://doi. org/10.1007/s11325-013-0809-4.

73. Harper RM, Kumar R, Macey PM, et al. Functional neuroanatomy and sleep-disordered breathing: implications for autonomic regulation. Anat Rec (Hoboken). 2012;295(9):1385-95. https:// doi.org/10.1002/ar.22514.

74. Gooley JJ, Mohapatra L, Twan DCK. The role of sleep duration and sleep disordered breathing in gestational diabetes mellitus. Neurobiol Sleep Circadian Rhythms. 2018;28(4):34-43. https:// doi.org/10.1016/j.nbscr.2017.11.001.

75. Joels M, Baram TZ. The neuro-symphony of stress. Nat Rev Neurosci. 2009;10:459-66. https://doi.org/10.1038/nrn2632.

76. Sapolsky RM, Romero LM, Munck AU. How do glucocorticoids influence stress responses? Integrating permissive, suppressive, stimulatory, and preparative actions. Endocr Rev. 2000;21:55-89. https://doi.org/10.1210/edrv.21.1.0389.

77. Munck A, Guyre PM, Holbrook NJ. Physiological functions of glucocorticoids in stress and their relation to pharmacological actions. Endocr Rev. 1984;5:25-44. https://doi.org/10.1210/ edrv-5-1-25.

78. Oyola MG, Handa RJ. Hypothalamic-pituitary-adrenal and hypothalamic-pituitary-gonadal axes: sex differences in regulation of stress responsivity. Stress. 2017;20:476-94. https://doi.org/10. 1080/10253890.2017.1369523.

79. Bublitz MH, Bourjeily G, D’Angelo C, et al. Maternal sleep quality and diurnal cortisol regulation over pregnancy. Behav Sleep Med. 2018;16:282-93. https://doi.org/10.1080/15402002.2016. 1210147.

80. Steiger A. Sleep and the hypothalamo-pituitary-adrenocortical system. Sleep Med Rev. 2002;6:125-38. https://doi.org/10.1016/ 0960-5428(95)00003-k.

81. Szelenyi J, Vizi ES. The catecholamine cytokine balance: interaction between the brain and the immune system. Ann N Y Acad Sci. 2007;1113:311-24. https://doi.org/10.1196/annals.1391.026.

82. Venihaki M, Dikkes P, Carrigan A, et al. Corticotropin-releasing hormone regulates IL-6 expression during inflammation. J Clin Invest. 2001;108:1159-66. https://doi.org/10.1172/JCI12869.

83. Rafacho A, Ortsäter H, Nadal A, et al. Glucocorticoid treatment and endocrine pancreas function: implications for glucose homeostasis, insulin resistance and diabetes. J Endocrinol. 2014;223(3):R49-62. https://doi.org/10.1530/JOE-14-0373.

84. Bozic J, Galic T, Supe-Domic D, et al. Morning cortisol levels and glucose metabolism parameters in moderate and severe obstructive sleep apnea patients. Endocrine. 2016;53:730-9. https://doi.org/10.1007/s12020-016-0925-6.

85. LeWinn KZ, Stroud LR, Molnar BE, et al. Elevated maternal cortisol levels during pregnancy are associated with reduced childhood IQ. Int J Epidemiol. 2009;38:1700-10. https://doi.org/10. 1093/ije/dyp200.

86. Hillhouse EW, Grammatopoulos DK. Role of stress peptides during human pregnancy and labour. Reproduction. 2002;124:3239. https://doi.org/10.1530/rep.0.1240323.

87. Challis JR, Sloboda D, Matthews SG, et al. The fetal placental hypothalamic-pituitary-adrenal (HPA) axis, parturition and post natal health. Mol Cell Endocrinol. 2001;185:135-44. https://doi. org/10.1016/s0303-7207(01)00624-4.

88. Bourjeily G, Butterfield K, Curran P, et al. Obstructive sleep apnea is associated with alterations in markers of fetoplacental wellbeing. J Matern Fetal Neonatal Med. 2015;28:262-6. https:// doi.org/10.3109/14767058.2014.913131.

89. Bourjeily G, Curran P, Butterfield K, et al. Placenta-secreted circulating markers in pregnant women with obstructive sleep apnea. J Perinat Med. 2015;43:81-7. https://doi.org/10.1515/ jpm-2014-0052.
90. Ravishankar S, Bourjeily G, Lambert-Messerlian G, et al. Evidence of placental hypoxia in maternal sleep disordered breathing. Pediatr Dev Pathol. 2015;18:380-6. https://doi.org/10.2350/ 15-06-1647-OA.1.

91. Miehle K, Stepan H, Fasshauer M. Leptin, adiponectin and other adipokines in gestational diabetes mellitus and pre-eclampsia. Clin Endocrinol (Oxf). 2012;76(2-11):94. https://doi.org/10. 1111/j.1365-2265.2011.04234.x.

92. Gonnissen HK, Hursel R, Rutters F, et al. Effects of sleep fragmentation on appetite and related hormone concentrations over $24 \mathrm{~h}$ in healthy men. Br J Nutr. 2013;109(4):748-56. https://doi. org/10.1017/S0007114512001894.

93. Charles LE, Gu JK, Andrew ME, et al. Sleep duration and biomarkers of metabolic function among police officers. J Occup Environ Med. 2011;53:831-7. https://doi.org/10.1097/JOM. 0b013e31821f5ece.

94. Aro M, Anttalainen U, Kurki S, et al. Gender-specific change in leptin concentrations during long-term CPAP therapy. Sleep Breath. 2020;24(1):191-9. https://doi.org/10.1007/ s11325-019-01846-y.

95. Xu X, Xu J. Effects of different obesity-related adipokines on the occurrence of obstructive sleep apnea. Endocr J. 2020;67(5):485500. https://doi.org/10.1507/endocrj.EJ20-0036.

96. Cuhadaroglu C, Utkusavas A, Ozturk L, et al. Effects of nasal CPAP treatment on insulin resistance, lipid profile, and plasma leptin in sleep apnea. Lung. 2009;187:75-81. https://doi.org/10. 1007/s00408-008-9131-5.

97. Kapustin RV, Chepanov SV, Babakov VN, et al. Maternal serum leptin, adiponectin, resistin and monocyte chemoattractant protein-1 levels in different types of diabetes mellitus. Eur J Obstet Gynecol Reprod Biol. 2020;254:284-91. https://doi.org/10. 1016/j.ejogrb.2020.09.050.

98. Xiao WQ, He JR, Shen SY, et al. Maternal circulating leptin profile during pregnancy and gestational diabetes mellitus. Diabetes Res Clin Pract. 2020;161:108041. https://doi.org/10.1016/j.diabr es.2020.108041.

99. McLachlan KA, O’Neal D, Jenkins A, et al. Do adiponectin, TNFalpha, leptin and CRP relate to insulin resistance in pregnancy? Studies in women with and without gestational diabetes, during and after pregnancy. Diabetes Metab Res Rev. 2006;22(2):131-8. https://doi.org/10.1002/dmrr.591.

100. Simmons D, Breier BH. Fetal overnutrition in polynesian pregnancies and in gestational diabetes may lead to dysregulation of the adipoinsular axis in offspring. Diabetes Care. 2002;25(9):1539-44. https://doi.org/10.2337/diacare.25.9.1539.

101. Yu JC, Berger P (2011) 3rd: sleep apnea and obesity. S D Med No: 28-34

102. Schwartz AR, Patil SP, Laffan AM, et al. Obesity and obstructive sleep apnea: pathogenic mechanisms and therapeutic approaches. Proc Am Thorac Soc. 2008;5(2):185-92. https://doi.org/10.1513/ pats.200708-137MG.

103. Yen IW, Lee CN, Lin MW, et al. Overweight and obesity are associated with clustering of metabolic risk factors in early pregnancy and the risk of GDM. PLoS ONE. 2019;14(12):e0225978. https://doi.org/10.1371/journal.pone.0225978.

104. Kirwan JP, Hauguel-De Mouzon S, et al. TNF-alpha is a predictor of insulin resistance in human pregnancy. Diabetes. 2002;51:2207-13. https://doi.org/10.2337/diabetes.51.7.2207.

105. Ategbo JM, Grissa O, Yessoufou A, et al. Modulation of adipokines and cytokines in gestational diabetes and macrosomia. J Clin Endocrinol Metab. 2006;91:4137-43. https://doi.org/10. 1210/jc.2006-0980.

106. Sehgal A, Behl T. Targeting NLRP3 inflammasome as a chief instigator of obesity, contributing to local adipose tissue inflammation and insulin resistance. Environ Sci 
Pollut Res Int. 2021;28(32):43102-13. https://doi.org/10.1007/ s11356-021-14904-4.

107. Galic S, Oakhill JS, Steinberg GR. Adipose tissue as an endocrine organ. Mol Cell Endocrinol. 2010;316:129-39. https://doi. org/10.1016/j.mce.2009.08.018.

108. Morooka N, Ueguri K, Yee KKL, et al. Androgen-androgen receptor system improves chronic inflammatory conditions by suppressing monocyte chemoattractant protein-1 gene expression in adipocytes via transcriptional regulation. Biochem Biophys Res Commun. 2016;477(4):895-901. https://doi.org/10.1016/j. bbrc.2016.06.155.

109. Shimobayashi M, Albert V, Woelnerhanssen B, et al. Insulin resistance causes inflammation in adipose tissue. J Clin Invest. 2018;128(4):1538-50. https://doi.org/10.1172/JCI96139.

110. Luo ZL, Ren JD, Huang Z, et al. The role of exogenous hydrogen sulfide in free fatty acids induced inflammation in macrophages. Cell Physiol Biochem. 2017;42(4):1635-44. https://doi.org/10. 1159/000479405.

111. Sourris KC, Lyons JG, de Courten MP, et al. c-Jun NH2-terminal kinase activity in subcutaneous adipose tissue but not nuclear factor- $\kappa \mathrm{B}$ activity in peripheral blood mononuclear cells is an independent determinant of insulin resistance in healthy individuals. Diabetes. 2009;58:1259-65. https://doi.org/10.2337/ db0837/db08-1725.

112. Johns EC, Denison FC. Sleep disordered breathing in pregnancy: a review of the pathophysiology of adverse pregnancy outcomes. Acta Physiol (Oxf). 2020;229(2):e13458. https://doi.org/10. 1111/apha.13458.

113. Morariu EM, Chasens ER, Strollo PJ, et al. Effect of continuous positive airway pressure (CPAP) on glycemic control and variability in type 2 diabetes. Sleep Breath. 2017;21:145-7. https:// doi.org/10.1007/s11325-016-1388-y.

114. Qureshi A, Ballard RD (2003) Obstructive sleep apnea. J Allergy Clin Immunol 112(4): 643-51; quiz 652. https://doi.org/10. 1016/j.jaci.2003.08.031

115. Mokhlesi B, Grimaldi D, Beccuti G, et al. Effect of one week of 8-hour nightly continuous positive airway pressure treatment of obstructive sleep apnea on glycemic control in type 2 diabetes: a proof-of-concept study. Am J Respir Crit Care Med. 2016;194:516-9. https://doi.org/10.1164/rccm.201602-0396LE.

116. Mokhlesi B, Grimaldi D, Beccuti G, et al. Effect of one week of CPAP treatment of obstructive sleep apnoea on 24-hour profiles of glucose, insulin and counter-regulatory hormones in type 2 diabetes. Diabetes Obes Metab. 2017;19:452-6. https://doi.org/ 10.1111/dom.12823.

117. Sharma SK, Agrawal S, Damodaran D, et al. CPAP for the metabolic syndrome in patients with obstructive sleep apnea. N Engl J Med. 2011;365(24):2277-86. https://doi.org/10.1056/NEJMo a1103944.

118. West SD, Nicoll DJ, Wallace TM, et al. Effect of CPAP on insulin resistance and $\mathrm{HbA1c}$ in men with obstructive sleep apnoea and type 2 diabetes. Thorax. 2007;62(11):969-74. https://doi.org/10. 1136/thx.2006.074351.

119. Schäfer H, Pauleit D, Sudhop T, et al. Body fat distribution, serum leptin, and cardiovascular risk factors in men with obstructive sleep apnea. Chest. 2002;122(3):829-39. https://doi.org/10. 1378/chest.122.3.829.

120. Carnelio S, Morton A, McIntyre HD. Sleep disordered breathing in pregnancy: the maternal and fetal implications. J Obstet Gynaecol. 2017;37(2):170-8. https://doi.org/10.1080/01443615. 2016.1229273.

121. Poyares D, Guilleminault C, Hachul H, et al. Pre-eclampsia and nasal CPAP: part 2. Hypertension during pregnancy, chronic snoring, and early nasal CPAP intervention. Sleep Med. 2007;9:15-21. https://doi.org/10.1016/j.sleep.2007.04.019.

122. Guilleminault C, Kreutzer M, Chang JL. Pregnancy, sleep disordered breathing and treatment with nasal continuous positive airway pressure. Sleep Med. 2004;5(1):43-51. https://doi.org/10. 1016/j.sleep.2003.07.001.

123. Li C, Zhang XL, Yuan P, et al. Clinical significance and intervention study of serum interleukin 18 in preeclampsia patients with coexisting obstructive sleep apnea. Zhonghua Jie $\mathrm{He} \mathrm{He} \mathrm{Hu} \mathrm{Xi}$ Za Zhi. 2012;35(7):503-6.

124. Piper AJ, Grunstein RR. Obesity hypoventilation syndrome: mechanisms and management. Am J Respir Crit Care Med. 2011;183(3):292-8.

125. Mokhlesi B. (2010) Obesity hypoventilation syndrome: a stateof-the-art review. Respir Care. 2010;55(10):1347-62.

126. Newmarch W, Weiler M, Casserly B. Obesity cardiomyopathy: the role of obstructive sleep apnea and obesity hypoventilation syndrome. Ir J Med Scib. 2019;188(3):783-90. https://doi.org/ 10.1007/s11845-018-01959-5. 